\title{
A Centralized Algorithm with Collision Avoidance for Trajectory Planning in Preflight Stage
}

\author{
Zheng Xiang $\mathbb{D}^{1},{ }^{1}$ Wenqi Zhang $\mathbb{D}^{1}{ }^{1}$ Deyang He $\mathbb{D}^{1,2}$ and Yu Tang $\mathbb{D}^{3}$ \\ ${ }^{1}$ School of Air Traffic Management, Civil Aviation Flight University of China, Sichuan Guanghan 618307, China \\ ${ }^{2}$ China Southern Airlines Company Limited, Guangdong Guangzhou 510405, China \\ ${ }^{3}$ Chengdu Airlines, Sichuan Chengdu 610042, China
}

Correspondence should be addressed to Wenqi Zhang; fxxy14zwq@163.com

Received 20 November 2020; Revised 8 December 2020; Accepted 24 December 2020; Published 7 January 2021

Academic Editor: Paolo Castaldi

Copyright (c) 2021 Zheng Xiang et al. This is an open access article distributed under the Creative Commons Attribution License, which permits unrestricted use, distribution, and reproduction in any medium, provided the original work is properly cited.

In order to better understand pretactical phase flow management with the flight plan centralized processing at its core, based on the flight plan centralized processing system and track-based operation, the aircraft's $4 \mathrm{D}$ trajectory planning challenges require a deeper level of analysis. Firstly, through establishing a flight performance prediction model, in which the flight plan data is extracted and the time when an aircraft passed a specified waypoint is calculated, a $4 \mathrm{D}$ flight prediction can be derived. Secondly, the air traffic flow of the waypoint is calculated, and a converging point along a flight route is selected. Through adjusting the time and speed of the aircraft passing this point, conflict between aircraft is avoided. Finally, the flight is verified by CCA1532, with the connecting flight plan centralized processing center set in line with the company's requirements. The results demonstrate that according to flight plans, the $4 \mathrm{D}$ trajectory of the aircraft can be predicted with the nearest minute and second, and the flow of a total of 20 aircraft within one hour before and after the passage of CCA1532 at key point WADUK can be calculated. When there is a conflict of $88 \mathrm{~s}$ between the convergence point and flight $\mathrm{B}$, the speed of B aircraft is adjusted from $789 \mathrm{~km} / \mathrm{h}$ to $778 \mathrm{~km} / \mathrm{h}$, and the time of passing the WADUK point is increased by $7 \mathrm{~s}$, thereby realizing the conflict-free trajectory planning of the two flights.

\section{Introduction}

As air traffic increases, flight delays and controller workload have increased. China has proposed a new generation of air traffic management systems with TBO (track-based operation) as its core, establishing a centralized processing center for flight plans. The combination of the two measures achieves flow management and trajectory planning of the pretactical and strategic stages and has become an effective means to improve the efficiency of airspace operations with less separation and higher air traffic flow. In addition, other benefits include realizing the sequencing and scheduling of flights, conflict detection and release, accurate aircraft transit time, and coordinated release and decision-making between the control center and airlines.

Research on trajectory planning includes proposing aerodynamic models and kinematic equations for trajectory forecasting [1]. Literature [2] proposed a hybrid estimation algorithm; however, it did not consider the performance of the aircraft type, making it is difficult to ensure the accuracy of trajectory predictions. In terms of conflict relief, the main issues are changing altitude, speed, and course. Changes in flight altitude can effectively resolve conflicts, but climbing and traversing altitude levels can easily cause interference with other aircraft and increase controller workload. The method of speed regulation has been shown to be more conducive to the processing of flight plans and coordinated decision-making with airlines. Published literature proposed [3] using aircraft-based ADS-B data Dhief to establish a speed-based conflict relief model; however, the article does not consider fuel consumption and flight path prediction, with further verification needed. In 2012, Lu proposed Petri net-based methods with maximum algebraic to conduct trajectory prediction and conflict resolution for multiple aircraft conflicts in the terminal area, principally through establishing discrete and continuous hybrid trajectory planning 
models and set services. In the interim, each interval serves an aircraft, and conflict relief of waypoints is realized in the terminal area based on time and speed [4]. Chaimatanan et al. proposed adjusting the take-off time, horizontal trajectory, and altitude to resolve potential trajectory conflicts between aircraft during the strategic phase. However, altitude allocation can only resolve conflicts during the cruise phase of the aircraft, so it is generally combined with other conflict resolution methods to resolve conflicts across the entire track [5]. In 2016, Heinz Erzberger of the NASA AMES Center proposed a design method and basic algorithm for a future system with high autonomy in the terminal airspace, using a trajectory and time allocation algorithm. The main purpose of this algorithm is to resolve conflicts and avoid dangerous convective weather. The algorithm is used to solve the conflict caused by the loss of aircraft separation, considering the situation including speed, same altitude level, and altitude change. It also provides a means to redistribute the approach of aircraft to the runway in order to reduce delays. These algorithms provide a method for generating conflict-free trajectory planning for traffic in the terminal area. Using Dallas/Fort Worth International Airport and Dallas Love Field, the research team was able to successfully simulate the arrival and departure of aircraft traffic [6].

The main focus of the models considered in the previous research is to predict the flight path with only limited focus on predicting the passing time of the aircraft, with the verification of simulations based on assumptions and lacking reference to the flight plan. Based on flight plans, this paper predicts the trajectory of the aircraft's transit time from the perspectives of model construction, performance, and transit time. After taking the convergent waypoint as the object, analyzing the trajectory of the two flights at the same level, establishing a protection zone, and judging flight conflict, we use a speed regulation method to resolve conflicts and realize the pretactical flow management.

\section{Centralized Flight Plan Processing and Trajectory Planning}

Trajectory planning mainly refers to the description of airspace environment, trajectory prediction, and conflict-free trajectory planning [7]. The research goal of trajectory planning is mainly to ensure aircraft flight safety, while considering various constraints, to provide an optimal route for flights, reducing conflicts and route changes, and limiting regulatory intervention.

The flight plan refers to providing air traffic service units with flight information about the aircraft completing a flight. It is usually produced by a dispatcher of the company and provided to the flight crew; it typically includes data such as the time of shifting gear, payload and balance, fuel quantity, weather data, route data, aircraft type, navigation notice among other data.

China has proposed the establishment of an air traffic control system operating system based on the flight planning service core of the National Flight Planning Unified Processing Center (NFPS) [8]. The trajectory planning based on the centralized processing of the flight plan in the pretactical phase means that the airspace user can determine the operating parameters of the entire aircraft after receiving the flight plan from anywhere several months to several hours prior to take-off, obtaining the flight profile and flight path prediction of the aircraft. The altitude or speed of the aircraft operating in certain airspace is adjusted to achieve conflict-free operation. The specific steps are that the aircraft operator or agent submits the flight plan of the flight to the flight plan central processing center system at a SITA or AFTN address at least two and a half hours prior to EOBT. The system performs syntax and semantic checks on each submitted flight plan, extracting accurate altitude, time, and speed information of flight crossing waypoints from the track model data, and generates flight track profiles through calculation, enabling conflict-free planning [9]. Finally, trajectory planning instructions are distributed and fed back to the control unit, aircraft operator, and flight crew. It can also provide flight planning data to the tower electronic process bill, air traffic control cooperative decision-making CDM, and AMAN/DMAN sorting of arrivals and departures, supporting national strategic, pretactical, tactical, and postevent flow management at various stages to achieve airspace capacity analysis and evaluation, optimizing operating efficiency. The process is shown in Figure 1.

\section{Aircraft Trajectory Prediction Based on Centralized Processing of Flight Plans}

Aircraft trajectory prediction chiefly uses BADA prediction model data and aircraft transit time prediction as its main components [10], typically based on the country's navigation data compilation route for horizontal, speed and altitude profile prediction, and key point flow prediction model.

\subsection{Trajectory Prediction Based on BADA}

3.1.1. Horizontal Trajectory. An aircraft's flight trajectory is projected in both horizontal and vertical directions. Judging from the horizontal projection of the track, the horizontal track is to connect the waypoints on the route with a straight line and turn around at or near a waypoint to continue straight flight, building a turn model at the junction of the flight segments [3]. General flight uses inscribed turning points as shown in Figure 2.

The method for calculating the heading angle is as follows: calculate the center angle $\alpha$ of BC. The distance the aircraft needs to fly can be calculated based on the flight time $t$ and speed $v$ in the BC segment. It is known that the OC heading angle is $\delta$, and the $\mathrm{AB}$ heading angle is $\theta$, and the OC heading angle is obtained:

$$
\delta=\theta+\alpha-\frac{\pi}{2} .
$$

Turning angle during turning on horizontal track:

$$
R_{\mathrm{turn}}=\frac{V_{\mathrm{gs}}^{2}}{g \tan \phi} .
$$




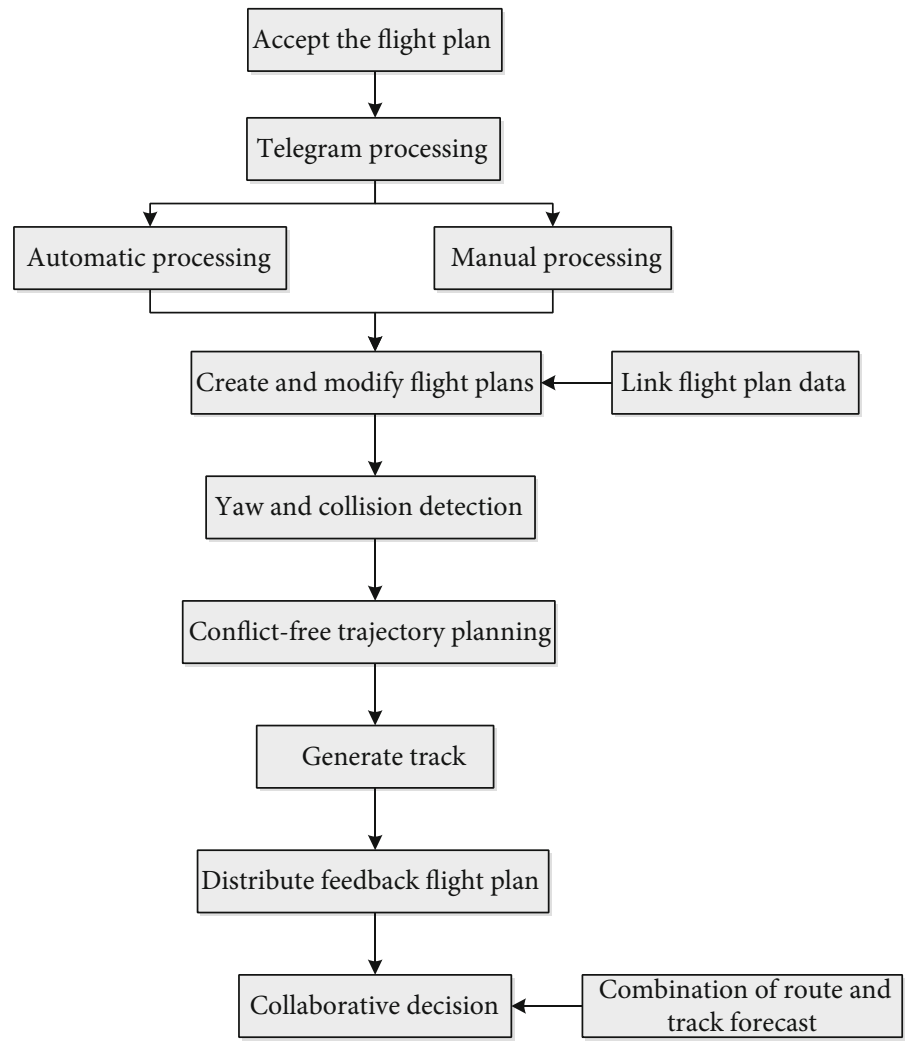

FIGURE 1: Flow chart of flight path planning for flight plan centralized processing system.

Among them, $R_{\text {turn }}$ is the turning radius, $V_{\mathrm{gs}}$ is the ground speed when turning, and $\varphi$ is the aircraft roll angle.

3.1.2. Vertical Profile. The vertical model of the aircraft is calculated based on the flight profile. The flight profile ignores the horizontal track and displays the altitude, speed, and time information of the aircraft in flight within a two-dimensional coordinated system. Aircraft operations are divided into three stages: climb, cruise, and descent [11]. These stages cover constant speed climb, constant Mach number climb, constant Mach number cruise, constant speed drop, constant Mach number drop, etc. The model equations are listed using Newton's second law and the principle of conservation of ability.

$$
\begin{aligned}
& \left\{\begin{array}{l}
m \frac{d v}{d t}=F \cos \left(\alpha+\phi_{p}\right)-D-m g \sin \theta, \\
m \frac{d \theta}{d t}=F \cos \left(\alpha+\phi_{p}\right)+L-m g \sin \theta
\end{array}\right. \\
& (F-D) v_{\mathrm{TAS}}=m g \frac{d h}{d t}=m v_{\mathrm{TAS}} \frac{d v_{\mathrm{TAS}}}{d t},
\end{aligned}
$$

where $m$ is the weight of the aircraft, $g$ is the acceleration of gravity, $h$ is the height of the aircraft, $F$ is the thrust of the engine, and the direction forms an installation angle $\varphi_{p}$ along the axis of the engine and the axis of the fuselage; $L$ is the lift, $L=C_{L} \times(1 / 2) \rho V^{2} S$, and $v$ is the flight speed; $D$ is the resistance; $\alpha$ is the angle of attack and $\theta$ is the track angle; $v_{T A S}$ is the vacuum speed.

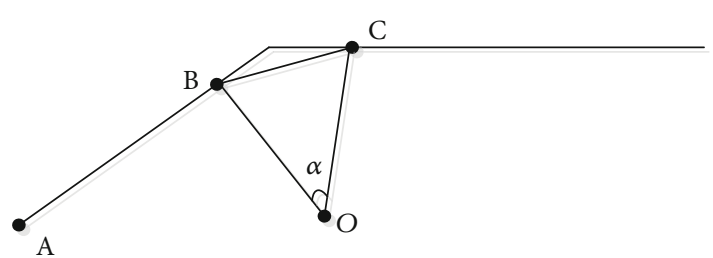

Figure 2: Arc trajectory algorithm.

Aircraft forces include total aerodynamic force $R$, gravity $W$, thrust $T$, lift $L$, resistance $D=(1 / 2) C_{D} \rho \cdot V_{\text {TAS }}^{2} \cdot S$, elevation angle $\alpha$, and path angle $\gamma$. The lift $L$ of an aircraft during flight depends on factors such as dynamic pressure and wing area $(S)$ [12]. $C_{D}$ and $C_{L}$ are the drag coefficient and lift coefficient given by the aircraft performance parameters.

Thrust Tdes, low $=C_{T \text { des,low }} \times T_{\text {max }, \lim b}$ during the cruise phase.

3.2. The Impact of Wind on Aircraft. According to the flight plan, the route mileage of a flight segment is $S$, the flight speed extracted in the flight plan is $V$, and the estimated time to fly over the waypoint is $S / V$.

The conversion formula of atmospheric temperature and aircraft vacuum speed:

$$
V_{\mathrm{TAS}}=1479.1 \times\left\{\frac{t_{\mathrm{LOC}}}{t_{\mathrm{MSL}}}\left[\left(1+\frac{\eta}{\delta}\right)^{1 / 3.5}-1\right]\right\}^{1 / 2} .
$$


In the formula:

$$
\begin{aligned}
& \eta=\left[1+0.2 \times\left(\frac{V_{\mathrm{CAS}}}{661.5}\right)^{2}\right]^{3.5}, \\
& \delta= \begin{cases}\left(1-6.087759 \times 10^{-6} \times h_{p}\right)^{5.25588}, & h_{p} \leq 30689 \mathrm{ft}, \\
0.2233609 \times \exp \left[\frac{30689-h_{p}}{20805.8}\right], & h_{p}>30689 \mathrm{ft} .\end{cases}
\end{aligned}
$$

Among them, $V_{\text {TAS }}$ refers to the vacuum speed; $V_{\text {CAS }}$ refers to the calibrated airspeed; $t_{\mathrm{LOC}}$ refers to the actual temperature of the location of the aircraft; $t_{\mathrm{MSL}}=288.15 \mathrm{~K}$ refers to the standard air pressure temperature at sea level; $h_{p}$ refers to the altitude of the aircraft.

High-altitude wind refers to the airflow in a horizontal flow state at a certain distance from the ground surface (generally, vertical airflow is not defined as high-altitude wind) [13]. The aircraft spends most of its time in the cruise phase and is affected by the high-altitude wind environment. The high-altitude wind speed directly affects the aircraft's ground speed and transit time. Aircraft are also affected by highaltitude wind and are often modeled by a heading speed triangle composed of three vectors of airspeed, ground speed, and wind [14]. The navigation wind vector triangle is shown in Figure 3 [15].

The relationship between aircraft ground speed, vacuum speed, and wind speed is

$$
V_{\mathrm{GS}}=V_{\mathrm{TAS}} \times \cos \theta+V_{\mathrm{WS}} \times \cos \alpha .
$$

Among them, $V_{\mathrm{GS}}$ refers to the ground speed, $V_{\mathrm{WS}}$ refers to the wind speed, $V_{\mathrm{WS}}=\sqrt{U^{2}+V^{2}}$, and $\alpha$ refers to the wind direction angle, when $180^{\circ} \geq \alpha \geq 90^{\circ}$ is upwind, when $V_{\mathrm{GS}}$ $<V_{\text {WS }}$ is downwind. $\theta$ represents the drift angle, the angle between $V_{\mathrm{GS}}$ and $V_{\mathrm{Ws}}$.

Substituting the formula into the formula, the relationship between aircraft ground speed and temperature and wind speed is obtained:

$$
V_{\mathrm{GS}}=1479.1 \times\left\{\frac{t_{\mathrm{LOC}}}{t_{\mathrm{MSL}}}\left[1+\frac{\eta}{\delta}\right]^{1 / 3.5}-1\right\}^{1 / 2} \times \cos \theta V_{\mathrm{WS}} \times \cos \alpha
$$

3.3. Aircraft Traffic Forecast. A waypoint is a node where the route crosses and converges. Traffic flow converges here, which is the crux of aircraft congestion and conflict [16]. Dependent on the flight plan, the flow of the waypoint passed by the flight is predicted, and the waypoint is provided for conflict-free trajectory planning. The intersection flow prediction model for aircraft flow based on the flight plan is

$$
\begin{aligned}
C_{E} & =F_{E i, Q, T, L}+F_{E j, Q, T, L}, \\
C_{W} & =F_{W i, Q, T, L}+F_{W j, Q, T, L}, \\
C_{Q, T} & =C_{E}+C_{W} .
\end{aligned}
$$

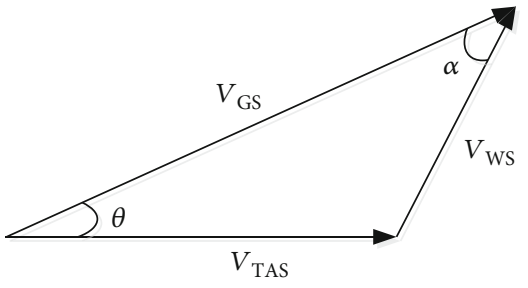

Figure 3: Apparent wind vector triangle.

Among them, $F_{E i, Q, T, L}$ is the number of the $i$ th route at the intersection $Q$ in the eastward direction of level $L$ in unit time $T ; F_{E j, Q, T, L}$ is the number of the $j$ th route at intersection $Q$ in the eastward direction of level $L$ in unit time $T ; F_{W i, Q, T, L}$ is the number of the $i$ th route at the intersection $Q$ in the westward direction of level $L$ in unit time $T ; F_{W j, Q, T, L}$ is the number of the $j$ th route at intersection $Q$ in the westward direction of level $L$ in unit time $T ; C_{E}$ is the total number of aircraft in each altitude unit time $T$ from east to west at intersection $Q ; C_{W}$ is the total number of aircraft in each altitude unit time $T$ from west to east at intersection $Q ; C_{Q, T}$ is the unit of each altitude at intersection $Q$, the total number of aircraft in time $T$.

\section{Aircraft Conflict Resolution Based on Centralized Processing of Flight Plans}

4.1. Problem Assumption. Conflict detection means that as the aircraft flies along a predetermined route, the ground monitoring system calculates the time when it passes the intersection based on the aircraft's position and speed information and determines whether the aircraft will collide with other aircraft passing through the intersection either at the intersection or at less than the minimum interval standard.

(1) The aircraft flies at a fixed altitude when cruising. Therefore, the problem of height change can be ignored, and the three-dimensional, multidimensional problem is simplified to a two-dimensional conflict resolution problem for processing

(2) The aircraft flies at a constant speed and flies on the centerline of the route, regardless of deviation factors, assuming that the range of flight speed is $20 \%$ of normal flight speed

(3) While the aircraft is in flight, the preset route of the flight plan remains unchanged, the aircraft is used as a mass point, and the direction of motion is the course of the route, without considering factors such as track error and route weather

(4) When the distance between two aircraft is $10 \mathrm{~km}(5 \mathrm{n}$ mile) the flight plan centralized processing system needs to carry out conflict-free trajectory planning. From the moment another aircraft enters the protected area, the two aircraft begin to clash. This paper studies two aircraft flying at the same altitude and converging waypoints, calculating the moment of 
conflict between the two aircraft, the duration of the conflict, and the conflict resolution [17]

4.2. Conflict-Free Planning Model. The two planes are A and $\mathrm{B}$, the speed is $V$, and the heading angle is $\alpha$. The coordinates of aircraft $\mathrm{A}$ are $\left(X_{\mathrm{A}}, Y_{\mathrm{A}}\right)$, and the coordinates of aircraft $\mathrm{B}$ are $\left(X_{\mathrm{B}}, Y_{\mathrm{B}}\right)$.

The distance between the two planes is $S$ :

$$
S=\sqrt{\left(X_{\mathrm{A}}-X_{\mathrm{B}}\right)^{2}+\left(Y_{\mathrm{A}}-Y_{\mathrm{B}}\right)^{2}} .
$$

In the formula:

$$
\begin{aligned}
& X_{\mathrm{A}}=X_{\mathrm{A}}(0)+V_{\mathrm{A}} t \cos \alpha_{\mathrm{A}}, \\
& Y_{\mathrm{A}}=Y_{\mathrm{A}}(0)+V_{\mathrm{A}} t \sin \alpha_{\mathrm{A}}, \\
& X_{\mathrm{B}}=X_{\mathrm{A}}(0)+V_{\mathrm{A}} t \cos \alpha_{\mathrm{A}} X_{\mathrm{A}}=X_{\mathrm{B}}(0)+V_{\mathrm{B}} t \cos \alpha_{\mathrm{A}}, \\
& Y_{\mathrm{B}}=Y_{\mathrm{B}}(0)+V_{\mathrm{B}} t \sin \alpha_{\mathrm{A}} .
\end{aligned}
$$

When $S \leq 10 \mathrm{~km}$, the aircraft conflicts.

The conflict of aircraft at the convergence point is a cross conflict; after passing through the intersection, it will evolve into a chasing conflict. In this case, the airspace environment becomes more complicated and needs to be optimized on the basis of the cross model.

When calculating the conflict between two aircraft at one time $t$, choose one aircraft as the reference standard, adjust its speed in advance at a waypoint before the key point, and ensure that the lateral separation between the two aircraft meets the minimum separation standard before and after reaching the convergent waypoint. The constraint condition of the aircraft speed adjustment range is $V_{\min } \leq V+\Delta V \leq$ $V_{\max }$. Based on the relative positions of the two airplanes, the constraint condition of the position change parameter $\Delta t$ is established, and the speed adjustment interval $\left[V_{1}, V_{2}\right]$ is determined. According to the parameters of the two airplanes, the speed vector difference of the two airplanes A and $\mathrm{B}$ at any time is obtained as

$$
V_{\mathrm{A}}-V_{\mathrm{B}}=\left\{\begin{array}{l}
\left(V_{\mathrm{A}}+\Delta V_{\mathrm{A}}\right) \cos \alpha_{\mathrm{A}} \\
\left(V_{\mathrm{A}}+\Delta V_{\mathrm{A}}\right) \sin \alpha_{\mathrm{A}}
\end{array}\right\}-\left\{\begin{array}{l}
\left(V_{\mathrm{B}}+\Delta V_{\mathrm{B}}\right) \cos \alpha_{\mathrm{B}} \\
\left(V_{\mathrm{B}}+\Delta V_{\mathrm{B}}\right) \sin \alpha_{\mathrm{B}}
\end{array}\right\} .
$$

Draw two straight lines parallel to vector $V_{\mathrm{A}}-V_{\mathrm{B}}$ and tangent to the circular protection area of aircraft $\mathrm{B}$, and call them the shadow of aircraft $B$ along the direction of aircraft A. When the protected area of aircraft A intersects with the shadow of aircraft B, a conflict will occur, as shown in Figure 4 [18].

After the two aircraft are tangent to one point after their protection area is expanded, when the angle between the common tangent line on the right side of the two aircraft and the heading of aircraft $B$ is greater than $\theta_{1}$, the two aircraft have no conflict, or when the common tangent line on the left is greater than $\theta_{2}$, the two aircraft have no conflict.

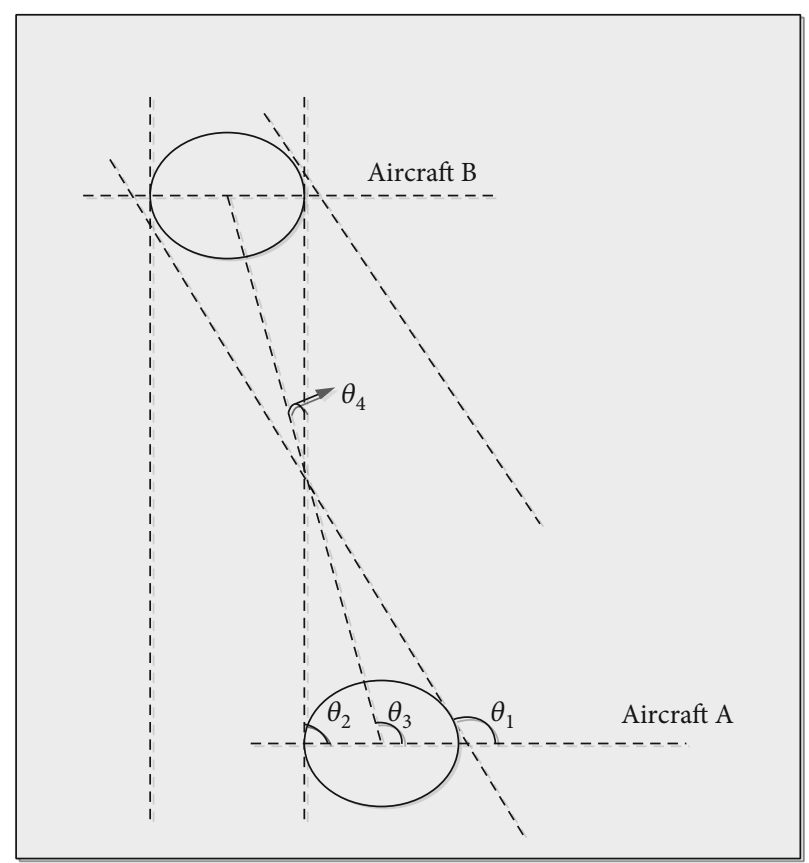

FIgURE 4: Conflict converging point operation status.

The angle between the center of the two aircraft and the common tangent of the two aircraft is $\theta_{3}$, and $\theta_{4}$ is the angle between the line of the center of the circle and aircraft $\mathrm{B}$. The two common tangents pass through the tangent points of the two expansion circles, and the distance between the two aircraft is $D$. Among them, the parameters are

$$
\begin{aligned}
& \theta_{1}=\theta_{3}+\theta_{4}, \\
& \theta_{2}=\theta_{4}-\theta_{3}, \\
& \theta_{3}=\arcsin \left(\frac{10}{D}\right) .
\end{aligned}
$$

The angle between the speed vector difference and the $x$ -axis is $\theta_{5}$, then

$$
\tan \theta_{5}=\frac{\left(V_{\mathrm{A}}+\Delta V_{\mathrm{A}}\right) \sin \alpha_{\mathrm{A}}-\left(V_{\mathrm{B}}+\Delta V_{\mathrm{B}}\right) \sin \alpha_{\mathrm{B}}}{\left(V_{\mathrm{A}}+\Delta V_{\mathrm{A}}\right) \cos \alpha_{\mathrm{A}}-\left(V_{\mathrm{B}}+\Delta V_{\mathrm{B}}\right) \cos \alpha_{\mathrm{B}}} .
$$

The speed control model of the aircraft is

$$
\begin{aligned}
& \Delta V=\min |\Delta V|, \quad i=1,2,3 \cdots n, \\
& \text { s.t. }\left\{\begin{array}{l}
V_{\min } \leq V+\Delta V \leq V_{\max }, \\
D \geq 10, \\
\tan \theta_{5} \geq \tan \theta_{1} .
\end{array}\right.
\end{aligned}
$$

When the aircraft resolves the conflict at the convergence point, it is also necessary to consider the catch-up situation when flying the same route. The model is when aircraft A reaches the convergence point, take $\mathrm{A}$ as the reference object and then adjust the speed according to the intersection point. Obtain the flight time $t$ to the convergence point of A: 


$$
\begin{aligned}
& x_{\mathrm{A}}(t)=x_{\mathrm{A}}^{0}+\cos \theta v, \\
& y_{\mathrm{A}}(t)=y_{\mathrm{A}}^{0}+\sin \theta v .
\end{aligned}
$$

The initial position of airplane $B$ relative to airplane $A$ is $X_{\mathrm{AB}}$ :

$$
X_{\mathrm{AB}}=\left(\begin{array}{c}
x_{\mathrm{A}}^{0}-x_{\mathrm{B}}^{0} \\
y_{\mathrm{A}}^{0}-y_{\mathrm{B}}^{0}
\end{array}\right) \text {. }
$$

The distance between the straight line and the origin is used to ensure that the two aircraft are flying at a safe distance. The distance between the two aircraft is the speed $V$ of aircraft $\mathrm{B}$, and the flight time is $t$. Then, the conflictfree speed regulation formula under the catch-up conflict is

$$
\begin{aligned}
& D-d=X_{\mathrm{AB}}+(V+\Delta V) t-d \geq 0, \\
& V_{\text {min }} \leq V+\Delta V \leq V_{\max } .
\end{aligned}
$$

When the aircraft is operating in the airspace, safety can only be guaranteed when the distance between the aircraft meets the minimum separation standard of $10 \mathrm{~km}$ and remains within a reasonable safety value. Figure 5 is a flow chart of conflict-free trajectory planning.

\section{Simulation}

The data in this experiment is real data from the Shanghai Flight Plan Processing Center. Since the flight plan processing center processes a lot of flight plans every day, this experiment only extracts the flight plan of flight CSC8963 for trajectory prediction. However, due to the limited number of flight plans processed by the simulation system, only changes in the conflict situation within a period of time are considered, and because the speed regulation method may cause flight conflicts in other airspaces on the entire flight route, this article does not consider any adjustments. For other flight conflicts caused by speed, only flight conflicts within limited airspace are considered.

Below is an extract of the flight plan report (FPL) from CCA1532 Chongqing Shuangbei Airport (ZUCK) to Nanjing Lukou Airport (ZSNJ) on October 22, 2019, from the Centralized Flight Plan Processing Center:

(FPL-CCA1532-IS

-B738/H-SDE1E2E3FGHIJ5M1RWYP2/EB1D1

-ZUCK0430

-K0800S1070 OGOMO/K0815S0750 H143 GAO/K0869 S1010 B213 WHA R343 MADUK/K0756S0630 R343 P282/ K0754S0630 R343 EKIMU

-ZSNJ0700 ZSPD ZSOF)

According to the flight plan, the equipment model is $\mathrm{B} 738$, the route is OGOMO-H143-GAO-B213-WHA-R343MADUK-R343-P282-R343-EKIMU, and the total length is approximately 1600 kilometers. The estimated time to withdraw the gear is 04:30 (UTC), and the estimated total flight time is $2 \mathrm{~h} 30 \mathrm{~m}$. This article estimates that the taxiing and off-runway waiting time is 15 minutes, and the take-off time is 04:45 (UTC). Assuming that under the international stan-

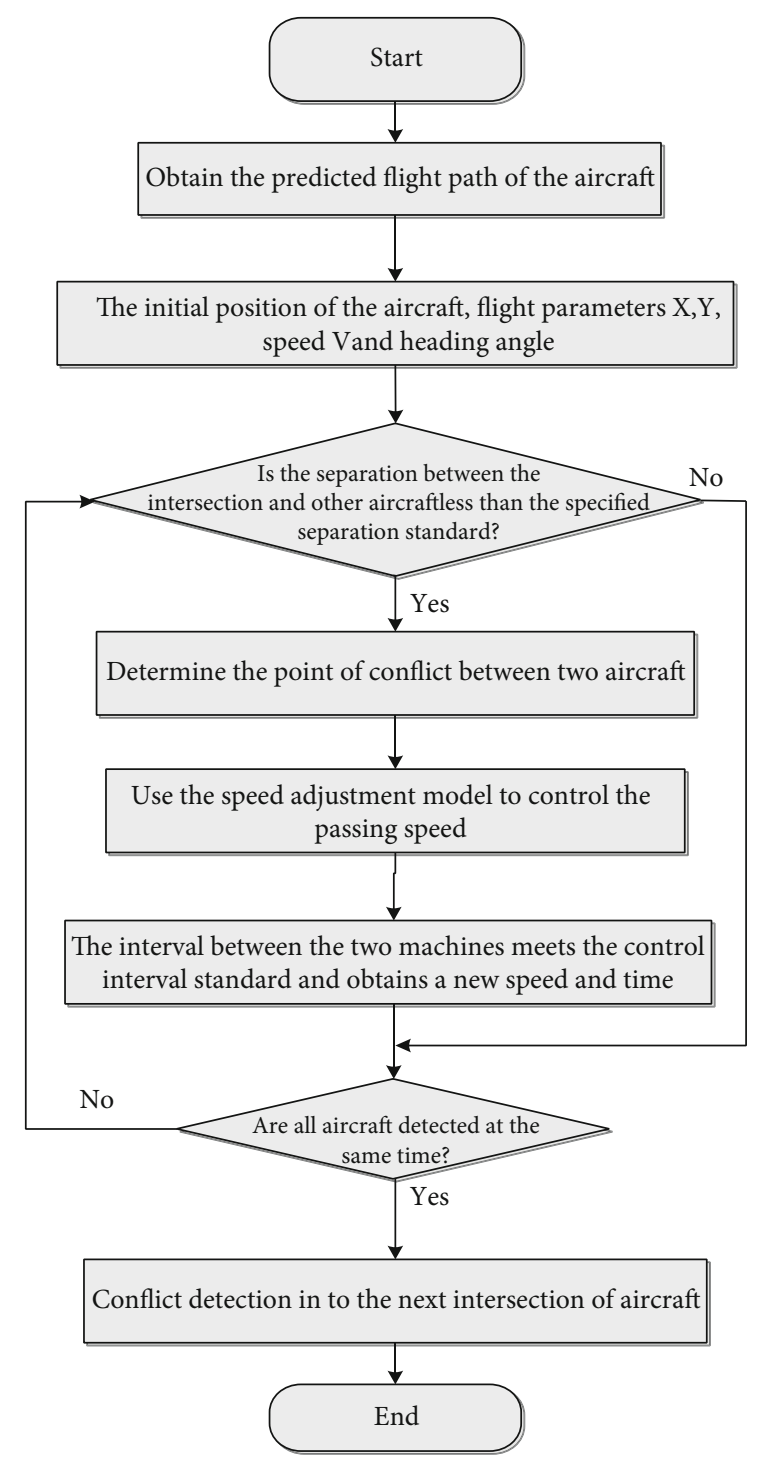

FIGURE 5: Route planning process of aircraft conflict-free trajectory.

dard atmosphere, the wind speed in the cruise section is $10 \mathrm{kt}$, and the sea pressure is corrected to $1013.25 \mathrm{hpha}$.

Select the real-time trajectory of the flight on October 22, 2019, and the comparison between the real-time key point data and the predicted flight profile parameters is shown in Table 1.

The prediction profile based on flight altitude, speed, and time is compared with the simulation results of the real-time trajectory. Due to real-time speed changes, passenger and fuel capacity, human factors, and changes in route weather, there will be differences in transit time, speed, and altitude. Comparison results are shown in Figure 6.

The Chongqing Airlines Operations Control Department submits the flight plan to the central processing center system for the flight plan at least two and a half hours before EOBT. The system sends the flight profile and trajectory prediction in the form of feedback telegram to the Chongqing Aviation Operation Control Center and distributes it to the control units including the airport tower, approach, and area adjustments that provide control services for the flight. 
TABLE 1: CCA1532 waypoint parameters.

\begin{tabular}{|c|c|c|c|c|c|c|c|}
\hline $\begin{array}{l}\text { Key } \\
\text { point }\end{array}$ & $\begin{array}{l}\text { Latitude and longitude } \\
\text { coordinates }\end{array}$ & $\begin{array}{l}\text { Forecast speed } \\
\qquad(\mathrm{km} / \mathrm{h})\end{array}$ & $\begin{array}{l}\text { Predicted } \\
\text { height }(\mathrm{m})\end{array}$ & $\begin{array}{l}\text { Forecast past } \\
\text { time (UTC) }\end{array}$ & $\begin{array}{l}\text { Real-time pass } \\
\text { (UTC) }\end{array}$ & $\begin{array}{l}\text { Real-time } \\
\text { height }(\mathrm{m})\end{array}$ & $\begin{array}{l}\text { Real-time speed } \\
(\mathrm{km} / \mathrm{h})\end{array}$ \\
\hline OGOMO & $105.005000 \mathrm{E} \quad 29.851667 \mathrm{~N}$ & 815 & 7500 & $4: 55: 15$ & $4: 55: 15$ & 6749 & 770 \\
\hline GAO & $106.188333 \mathrm{E} \quad 29.810000 \mathrm{~N}$ & 870 & 10100 & 5:06:05 & $5: 04: 50$ & 8876 & 910 \\
\hline WHA & $114.203333 \mathrm{E} \quad 29.781667 \mathrm{~N}$ & 870 & 10100 & 6:03:50 & $6: 04: 25$ & 10670 & 896 \\
\hline MADUK & $118.105000 \mathrm{E} \quad 30.718333 \mathrm{~N}$ & 755 & 6300 & 6:29:53 & $6: 29: 52$ & 10092 & 860 \\
\hline P282 & $119.366667 \mathrm{E} \quad 30.616667 \mathrm{~N}$ & 755 & 6300 & 6:38:54 & $6: 35: 58$ & 8879 & 849 \\
\hline SASAN & $120.320000 \mathrm{E} \quad 30.590000 \mathrm{~N}$ & 755 & 6300 & 6:45:01 & 6:43:02 & 6310 & 715 \\
\hline EKIMU & $121.110000 \mathrm{E} \quad 30.351667 \mathrm{~N}$ & 755 & 4500 & $6: 51: 20$ & $6: 50: 06$ & 144 & 637 \\
\hline
\end{tabular}
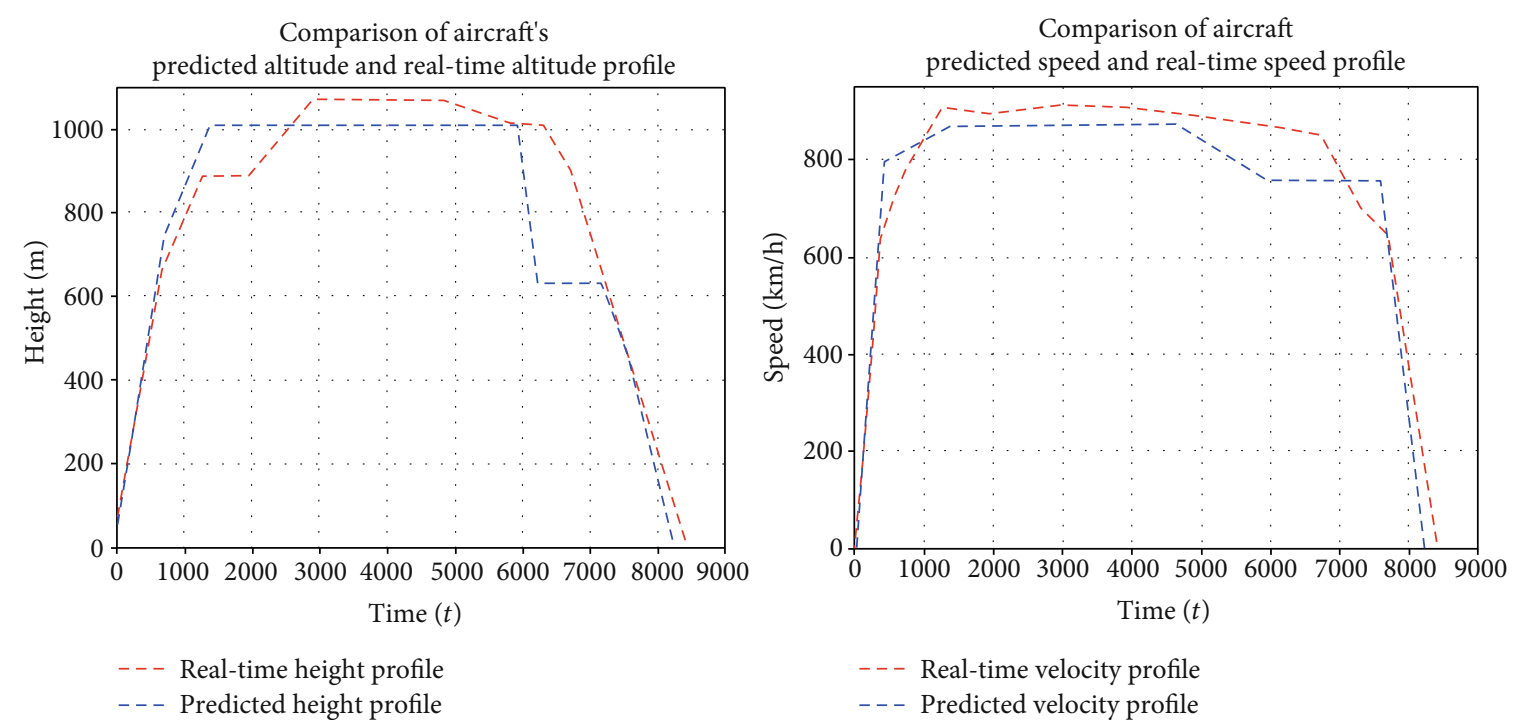

FIGURE 6: Comparison between real-time trajectory profile and trajectory prediction profile.

TABLE 2: Based on the flight plan, the flow of flights passing through WADUK point in the same time period.

\begin{tabular}{|c|c|c|c|c|c|c|c|}
\hline $\begin{array}{l}\text { Flight } \\
\text { number }\end{array}$ & $\begin{array}{c}\text { Pass WADUK } \\
\text { height }\end{array}$ & Speed & $\begin{array}{l}\text { Point time through } \\
\text { WADUK (UTC) }\end{array}$ & $\begin{array}{l}\text { Flight } \\
\text { number }\end{array}$ & $\begin{array}{c}\text { Pass WADUK } \\
\text { height }\end{array}$ & Speed & $\begin{array}{l}\text { Point time through } \\
\text { WADUK (UTC) }\end{array}$ \\
\hline CCA1948 & $9800 \mathrm{~m}$ & $840 \mathrm{~km} / \mathrm{h}$ & $7: 30: 24$ & CES2976 & $8900 \mathrm{~m}$ & $848 \mathrm{~km} / \mathrm{h}$ & $8: 05: 27$ \\
\hline CQH8888 & $10700 \mathrm{~m}$ & $850 \mathrm{~km} / \mathrm{h}$ & $7: 41: 30$ & CSC8963 & $10700 \mathrm{~m}$ & $780 \mathrm{~km} / \mathrm{h}$ & $8: 05: 45$ \\
\hline CHB6235 & $10100 \mathrm{~m}$ & $850 \mathrm{~km} / \mathrm{h}$ & $7: 50: 22$ & CES5475 & $8100 \mathrm{~m}$ & $805 \mathrm{~km} / \mathrm{h}$ & $8: 06: 27$ \\
\hline CCA4505 & $10100 \mathrm{~m}$ & $800 \mathrm{~km} / \mathrm{h}$ & 7:53:08 & CES5408 & $9500 \mathrm{~m}$ & $845 \mathrm{~km} / \mathrm{h}$ & 8:06:30 \\
\hline CES5436 & $9500 \mathrm{~m}$ & $0.78 \mathrm{M}$ & 7:53:09 & CSN6277 & $8450 \mathrm{~m}$ & $840 \mathrm{~km} / \mathrm{h}$ & $8: 06: 37$ \\
\hline CES9715 & $9500 \mathrm{~m}$ & $849 \mathrm{~km} / \mathrm{h}$ & $7: 57: 50$ & CUA5817 & $8900 \mathrm{~m}$ & $857 \mathrm{~km} / \mathrm{h}$ & $8: 15: 53$ \\
\hline CSZ8612 & $8500 \mathrm{~m}$ & $\begin{array}{c}0.78 \\
\text { Mach }\end{array}$ & $7: 58: 36$ & CSH9412 & $10700 \mathrm{~m}$ & $850 \mathrm{~km} / \mathrm{h}$ & $8: 15: 55$ \\
\hline DKH1120 & $9500 \mathrm{~m}$ & $847 \mathrm{~km} / \mathrm{h}$ & 8:00:14 & CCA157 & $10100 \mathrm{~m}$ & $0.78 \mathrm{M}$ & 8:19:07 \\
\hline CSC8629 & $10100 \mathrm{~m}$ & $869 \mathrm{~km} / \mathrm{h}$ & 8:00:50 & TBA9881 & $7500 \mathrm{~m}$ & $839 \mathrm{~km} / \mathrm{h}$ & $8: 25: 20$ \\
\hline CSZ9532 & $10100 \mathrm{~m}$ & $759 \mathrm{~km} / \mathrm{h}$ & 8:01:31 & CES9944 & $7500 \mathrm{~m}$ & $736 \mathrm{~km} / \mathrm{h}$ & $8: 29: 50$ \\
\hline
\end{tabular}

If we assume that flight CCA1532 is delayed by 1 hour and 30 minutes due to a thunderstorm in the field, then according to the flight plan centralized processing requirements when the flight delay time is greater than 15 minutes and less than 20 hours, the company should submit a delay report to the processing center, which the flight plan centralized processing center accepts no later than the EOBT in the current flight plan. The 20-hour delay report flight plan is received by the centralized processing center and has reexecuted track prediction, track planning, and key point flow statistics. The time of arriving at WADUK due to delay is 7:59:53 (UTC), and the flight plan information of the flight passing through WADUK point in the time period of 07:30-08:30 (UTC) is shown in Table 2. 
TABLE 3: Flight plan information.

\begin{tabular}{|c|c|c|c|c|c|c|c|c|}
\hline Number & $\begin{array}{l}\text { Flight } \\
\text { number }\end{array}$ & Airway & $\begin{array}{l}\text { Starting point (latitude and } \\
\text { longitude) }\end{array}$ & $\begin{array}{l}\text { Initial point time } \\
\text { (UTC) }\end{array}$ & $\begin{array}{l}\text { Time to reach MADUK } \\
\text { (UTC) }\end{array}$ & $\begin{array}{l}\text { Height } \\
(\mathrm{m})\end{array}$ & $\begin{array}{l}\text { Speed } \\
(\mathrm{m} / \mathrm{s})\end{array}$ & Course \\
\hline $\bar{A}$ & CSC8629 & B213 & $112.990070 \mathrm{E} 30.631215 \mathrm{~N}$ & $7: 52: 41$ & $8: 00: 50$ & 10100 & 241 & $86^{\circ}$ \\
\hline B & CSZ9532 & A581 & $\begin{array}{c}\text { 113.185000E 30.216667N } \\
(\text { GUGAM) }\end{array}$ & $7: 52: 41$ & 8:01:31 & 10100 & 219 & $61^{\circ}$ \\
\hline
\end{tabular}

Two flight position maps with
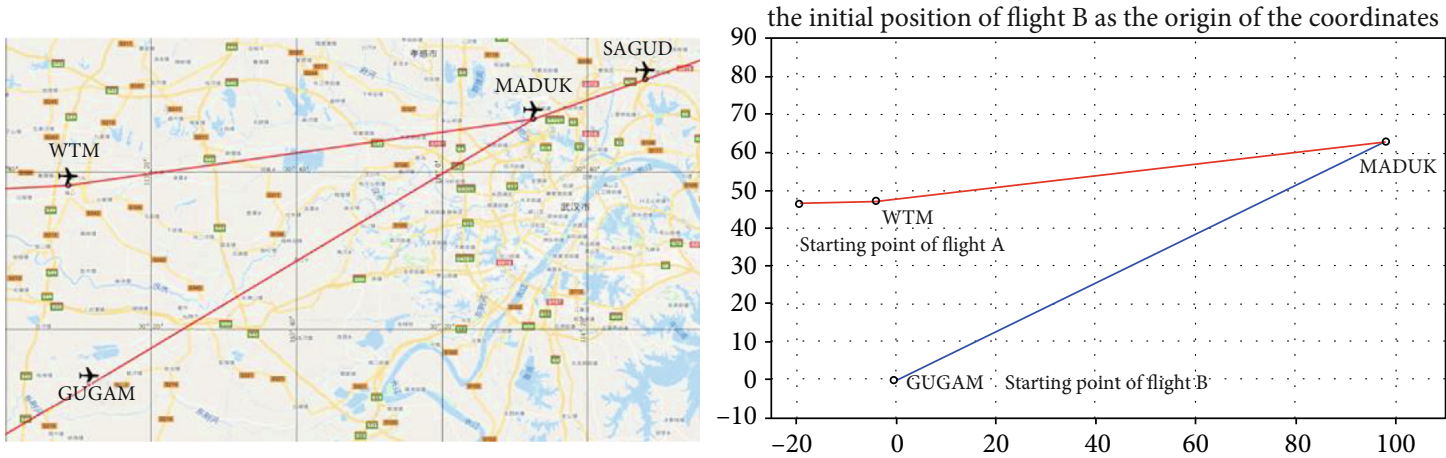

Figure 7: Two flight positions with the initial position of flight B as the coordinate origin.

According to the aircraft speed, it is estimated that the flight time between the two aircraft is $2 \mathrm{~min}$. The aircraft needs to assess whether a conflict exists. Both CEZ9532 and CSC8629 are conflicted within a factor of $2 \mathrm{~min}$ and $10100 \mathrm{~m}$, with the time and speed of the aircraft passing the convergence point needing to be adjusted in advance to achieve conflict-free trajectory planning. The maximum cruising speed of B738 is $954 \mathrm{~km} / \mathrm{h}$ as the maximum speed adjustment, and the minimum smooth speed is $470 \mathrm{~km} / \mathrm{h}$ as the minimum speed adjustment. Adjust the speed of aircraft B. Aircraft A's speed remains unchanged, taking the position of flight B (GUGAM) as the origin of coordinates and the time of arrival at GUGAM as the reference. At this time, flight A is located at B213, which is $14701 \mathrm{~m}$ from WTM $(30.701949,113.636543)$. The flight plan information of the two flights is shown in Table 3 , and the route map and two-dimensional coordinates are shown in Figure 7.

Using MATLAB to simulate, when $t=445 \mathrm{~s}$, the two machines conflict, which is less than the standard value of the minimum safe interval, and the relative position interval between the two machines is gradually reduced. When $t=489 \mathrm{~s}$, when aircraft A reaches the MADUK point, the distance in the conflict is $9030 \mathrm{~m}$, and the interval gradually increases. When $t=530 \mathrm{~s}$, aircraft $\mathrm{B}$ reaches the MADUK point, and the interval between the two aircraft is $9936 \mathrm{~m}$. Until $t=533 \mathrm{~s}$ conflict ends, the conflict time lasts for $88 \mathrm{~s}$, and therefore, speed adjustment is required. Figure 8 reflects a complete process in which two aircraft converge and conflict on the route from GUGAM to MADUK with the initial position GUGAM of the B aircraft as the starting point.

The simulation result shows that the speed of flight $B$ is $\Delta V_{B}=-3 \mathrm{~m} / \mathrm{s}$. The speed of flight $\mathrm{B}$ after speed adjustment is $216 \mathrm{~m} / \mathrm{s}$, which extends the time for aircraft $\mathrm{B}$ to pass

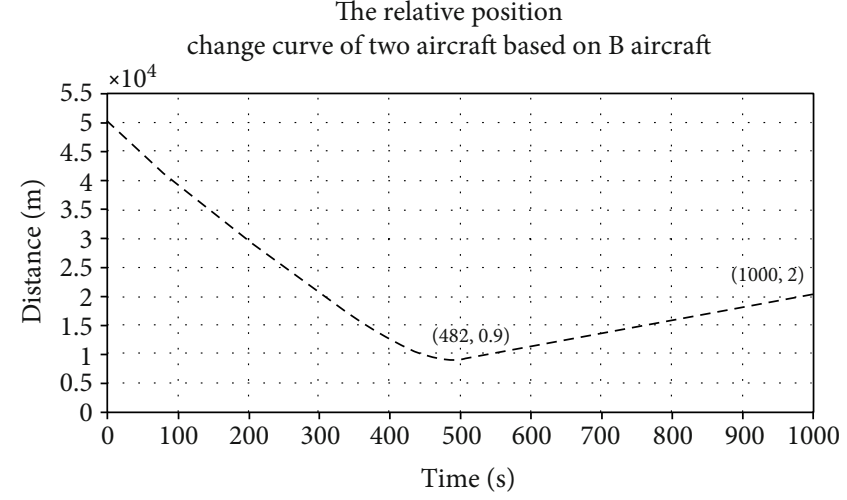

FIGURE 8: Change of relative position of flight based on B aircraft position.

WHA point by $7 \mathrm{~s}$, and the time for aircraft $B$ to pass MADUK to $537 \mathrm{~s}$. When the time for flight A to reach MADUK is $t=489 \mathrm{~s}$, the interval between the two aircraft is $10497 \mathrm{~m}$; when the time from B to MADUK point is $t=537$ $\mathrm{s}$, the interval between the two aircraft is $12.941 \mathrm{~km}$. Figure 9 shows the aircraft time and relative position changes after speed adjustment. By adjusting speed, it can be ensured that the two flights meet the required safety interval standard during any time on the route where the MADUK point converges, and after passing the MADUK point, there will be no chasing conflicts, realizing the freedom of the two aircraft.

When the flight plan centralized processing center handles this convergence conflict, the flight plan telegram of flight CSZ9532 needs to be reduced from GUGAM point to $778 \mathrm{~km} / \mathrm{h}$ from $789 \mathrm{~km} / \mathrm{h}$, and the time after MADUK point is increased by $7 \mathrm{~s}$, and finally arrives. The MADUK time is 8:01:38 (UTC) to ensure that the flight path with the 


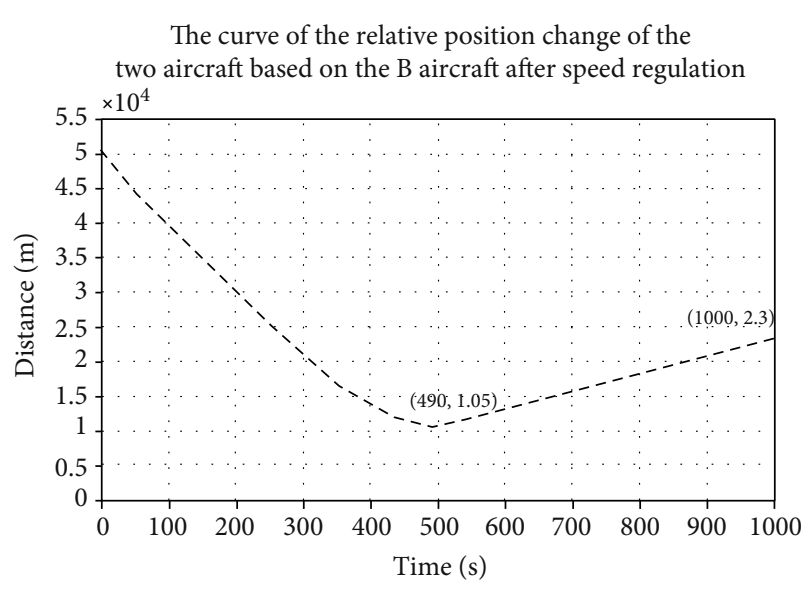

FIGURE 9: The relative position change of the two aircraft after the speed adjustment of the B aircraft.

CSZ9532 flight through the MADUK point realizes conflictfree trajectory planning after the delay of CSC8629.

Therefore, the revised flight plan is as follows:

(FPL-CCA1532-IS

-B738/H-SDE1E2E3FGHIJ5M1RWYP2/EB1D1

-ZUCK0430

-K0800S1070 OGOMO/K0815S0750 H143 GAO/K0869 S1010 B213 WHA R343 MADUK/K0789S0630 R343 P282/ K0754S0630 R343 EKIMU

-ZSNJ0700 ZSPD ZSOF)

The flight plan centralized processing center will feedback the revised flight plan of CSZ9532 to Air China's performance, dispatch, and related departments two hours prior to the flight's EOBT. The operation control center will recalculate the flight profile and fuel volume and other related data, informing the crew of the relevant changes, making necessary adjustments for anticollision and speed adjustment in GUGAM before take-off.

\section{Conclusion}

This paper combines the centralized processing of flight plans with trajectory-based operations, proposing flight trajectory planning under flow management during the pretactical stage. Firstly, the aircraft performance model is established, focusing on the aircraft passing time, aircraft profile, and trajectory prediction. Subsequently, a forecast of aircraft passing traffic is undertaken, and finally, the conflict-free trajectory planning of multiple aircraft is recorded and studied.

(1) This article establishes a flow forecast model for the convergence point in the cruise phase and establishes a conflict-free planning model for the convergence waypoint. By adjusting the speed of a waypoint before the convergence point, the time for the aircraft to pass the convergence point is effectively controlled

(2) The results of extracting the flight plan of CSC8963 for simulation and verification show that it can realize the trajectory planning of the aircraft in the pretactical stage and apply this to the centralized processing system of the flight plan

Through this research, it can effectively reduce the workload of the controller by reducing the need to monitor and issue instructions, providing greater scope to deal with potential conflicts before they occur, and improve flight safety and efficiency, which can be applied in practice. The data in this experiment are real data from the Shanghai Flight Planning Processing Center. As the integrity of the data continues to improve, the efficiency of problem solving will be further improved.

\section{Data Availability}

The data of the results of this study is related to the flight safety of the aircraft and has copyright; upon request, part of the data can be obtained from the corresponding author.

\section{Conflicts of Interest}

The authors declare that there are no conflicts of interest regarding the publication of this paper.

\section{Acknowledgments}

This research has won the horizontal scientific research project of Civil Aviation Flight University of China (H2018-14), the Open Fund Project of Key Laboratory of Flight Techniques and Flight Safety, CAAC (F2019KF06), the Postgraduate Scientific Research Innovation Project of Civil Aviation Flight University of China (X2020-30), and the Innovative Training of College Students Project (S201910624047) funding. The authors are very grateful for the support of these funds.

\section{References}

[1] C. Gong and W. Chan, "Using flight manual data to derive aero-propulsive models for predicting aircraft trajectories," in AIAA's Aircraft Technology, Integration, and Operations (ATIO) 2002 Technical Forum, 2002.

[2] J. Zhang, S. Dong, and X. Tang, "Track prediction based on hybrid estimation of state-dependent mode switching," System Theory and Practice, vol. 34, no. 11, pp. 2955-2964, 2014.

[3] I. Dhief, N. H. Dougui, D. Delahaye, and N. Hamdi, "Conflict resolution of North Atlantic air traffic with speed regulation," Transportation Research Procedia, vol. 27, no. 10, pp. 12421249, 2017.

[4] L. Zhiwei, "Multi-aircraft conflict-free 4D trajectory generation based on maximum algebra," Traffic Information and Safety, vol. 3, pp. 147-151, 2012.

[5] S. Chaimatanan, D. Delahaye, and M. Mongeau, "Aircraft 4D trajectories planning under uncertainties," in 2015 IEEE Symposium Series on Computational Intelligence, pp. 51-58, Cape Town, South Africa, 2015.

[6] H. Erzberger, T. Nikoleris, R. A. Paielli, and Y.-C. Chu, "Algorithms for control of arrival and departure traffic in terminal airspace," Proceedings of the Institution of Mechanical Engineers, Part G: Journal of Aerospace Engineering, vol. 230, no. 9, pp. 1762-1779, 2016. 
[7] X. Yang and B. Jiang, "Track-based operation: new ideas for future aviation operation modes," China Civil Aviation, vol. 151, pp. 45-47, 2013.

[8] X. Zheng, D. He, H. Gao, and W. Zhang, "Comparative study on centralized processing of Chinese and European flight plans," China Science and Technology Information, vol. 11, no. 9, pp. 35-37, 2019.

[9] Y. Guo, Y. Zhu, and Z. Huang, "Research on key technologies of civil aircraft track prediction," Journal of Civil Aviation University of China, vol. 25, no. 1, pp. 20-24, 2007.

[10] Euro Control Experimental Centre, User Manual for the Base of Aircraft Data(BADA), Euro Control Experimental Centre, 2010.

[11] M. Gao, Strategic Conflict Resolution Method and Model Research Based on 4D Trajectory, Nanjing University of Aeronautics and Astronautics, Nanjing, 2018.

[12] A. Olivares, M. Soler, and E. Staffetti, "Application of multiphase mixed integer optimal control in 4D trajectory planning in air traffic management," International Conference on Automation Application and Theory of Command and Control System, vol. 5, pp. 178-182, 2013.

[13] H. Thomas, H. Patrick, and S. Manuela, "Aircraft route forecasting under adverse weather condition," Meteorologische Zeitschrift, vol. 26, no. 2, pp. 189-206, 2016.

[14] J. Krozel, S. Penny, J. Prete, and J. S. B. Mitchell, “Automated route generation for avoiding deterministic weather in transition airspace," Journal of Guidance, Control, and Dynamics, vol. 30, no. 1, pp. 144-153, 2007.

[15] Y. Lu, Research on 4D Trajectory Generation and Simulation System of Initial Flight Plan, Nanjing University of Aeronautics and Astronautics, Nanjing, 2014.

[16] C. Wang, J. Guo, and Z. Shen, "4D track prediction method based on basic flight model," Journal of Southwest Jiaotong University, vol. 44, no. 2, pp. 295-300, 2009.

[17] X. Liu and S. Han, "The Delaunay method for free-flight conflict detection," Data Acquisition and Processing, vol. 17, no. 4, pp. 446-449, 2002.

[18] Y. Zhao, C. Lin, and H. Wang, "Research on the timing of cross-airway conflict resolution based on speed regulation method," Science Technology and Engineering, vol. 31, no. 13, pp. 9252-9257, 2013. 